\title{
PROTOCOLO DE INGRESSO DE ACERVOS ARQUEOLÓGICOS EM INSTITUIÇÕES DE GUARDA E PESQUISA: UMA PROPOSTA DO LÂMINA/UFPEL E DO MUSEU DE PORTO ALEGRE JOAQUIM FELIZARDO - RS
}

\author{
Jaime Mujica Sallés ${ }^{1}$ \\ Fernanda Bordin Tocchetto ${ }^{2}$ \\ Susana dos Santos Dode ${ }^{3}$ \\ Taciane Silveira Souza ${ }^{4}$ \\ Fabio Barreto da Silva ${ }^{5}$ \\ Márcia Regina Ribeiro Dutra ${ }^{6}$ \\ Eneri James Borges Medeiros ${ }^{7}$ \\ Clarice da Silva Alves ${ }^{8}$ \\ Bibiana Santos Domingues ${ }^{9}$
}

\section{RESUMO}

A situação do acervo arqueológico brasileiro sob responsabilidade de instituições de guarda encontra-se, em grande parte, distante de ser satisfatória. Esta premissa justifica-se não somente pela existência de reservas técnicas inapropriadas e/ou saturadas, mas também pela falta de recursos materiais e humanos especializados e pela carência de normas internas de regulação da entrada de novas coleções nas instituições. Muitas apresentam um estado de conservação desfavorável, com escassas informações associadas que atentam contra a interpretação e a extroversão deste patrimônio. Neste sentido, é apresentada, como instrumento de gestão, uma proposta de Protocolo de ingresso de acervos arqueológicos construída pelas equipes do Museu de Porto Alegre Joaquim Felizardo e do Laboratório Multidisciplinar de Investigação Arqueológica da UFPel (RS), com o intuito de contribuir para a preservação, interpretação e comunicação das coleções.

PALAVRAS-CHAVE: acervo arqueológico, salvaguarda, normas de ingresso, instrumento de gestão, proposta coletiva.

1 Coordenador Geral do Laboratório Multidisciplinar de Investigação Arqueológica (LÂMINA)/Universidade Federal de Pelotas. E-mail: mujica.jaime@gmail.com.

${ }^{2}$ Arqueóloga, Museu de Porto Alegre Joaquim Felizardo/Secretaria da Cultura de Porto Alegre (SMC). E-mail: fernandatocchetto@gmail.com.

${ }^{3}$ Conservadora-Restauradora Associada do LÂMINA. E-mail: susanadode@hotmail.com.

${ }^{4}$ Conservadora-Restauradora Associada do LÂMINA. E-mail: ciane_ta@hotmail.com.

${ }^{5}$ Conservador-Restaurador Associado do LÂMINA. E-mail: fabio_barretu@hotmail.com.

${ }^{6}$ Conservadora-Restauradora Associada do LÂMINA. E-mail: marcia.rdutra@hotmail.com.

${ }^{7}$ Técnico em Informática Associado do LÂMINA. E-mail: eneri.james@gmail.com.

8 Técnica em Cultura, Museu de Porto Alegre Joaquim Felizardo/SMC. E-mail: claricedsa@gmail.com.

${ }^{9}$ Estagiária, Museu de Porto Alegre Joaquim Felizardo/SMC. E-mail: bibiana-sd@hotmail.com.

\begin{tabular}{|l|l|l|l|l|l|l|}
\hline (C) Rev. Arqueologia Pública & Campinas, SP & v.11 & n.2 & p. 6 & Novembro/2017 & ISSN 2237-8294 \\
\hline
\end{tabular} 


\section{ABSTRACT}

The situation of Brazilian archaeological collection under responsibility of institutions of custodian in the country is found, largely, far from satisfactory. This premise is justified not only by the existence of inappropriate and/or saturated technical reserves, but also by the lack of specialized material and human resources, and by the deficiency of internal regulation norms for the entry of new collections into institutions. In this way, many have an unfavorable conservation status, with scarce information associated which would undermine the interpretation and extroversion of this patrimony. In this sense, a proposal for a Protocol for the entry of archaeological collections by the teams of the Museu de Porto Alegre Joaquim Felizardo e do Laboratório Multidisciplinar de Investigação Arqueológica da Universidade Federal de Pelotas (RS) is presented as a management tool. It was elaborated with the intention of contributing to the preservation of the state of the collections, their interpretation and communication.

KEYWORDS: archaeological collection, safeguard, rules of entry, management tool, collective proposal.

\section{RESUMEN}

La situación del acervo arqueológico brasileño bajo responsabilidad de instituciones de custodia se encuentra, en su gran mayoría, distante de ser satisfactoria. Esta premisa se justifica no solamente por la existencia de reservas técnicas inapropiadas y/o saturadas, más también por la falta de recursos materiales y humanos especializados; y por la carencia de normas internas de regulación de la entrada de nuevas colecciones en las instituciones. Muchas presentan un estado de conservación desfavorable, con escasas informaciones asociadas que van en contra de la interpretación y extroversión de este patrimonio. Por consiguiente, se presenta, como instrumento de gestión, una propuesta de Protocolo de ingreso de acervos arqueológicos, construida por los equipos del Museo de Porto Alegre Joaquim Felizardo y del Laboratorio Multidisciplinar de Investigación Arqueológica de la UFPel (RS), con el objetivo de contribuir para la preservación, interpretación y comunicación de las colecciones.

PALABRAS CLAVE: acervo arqueológico, salvaguarda, normas de ingreso, instrumento de gestión, propuesta colectiva.

\section{INTRODUÇÃO}

Durante os últimos anos, um crescente número de materiais arqueológicos tem ingressado em instituições de guarda e pesquisa, provenientes de investigações dos próprios museus, universidades e empresas de consultoria. Este elevado número de coleções tem criado uma série de demandas quanto à infraestrutura e aos recursos 
humanos e materiais para as instituições de salvaguarda, no intuito de garantir a elas a conservação, a documentação, o estudo e a extroversão.

O diálogo entre as áreas da arqueologia, conservação e museologia no que tange à salvaguarda é recente no Brasil, limitando o direcionamento de ações voltadas à preservação de acervos arqueológicos. Por um lado, arqueólogas/os com interesses voltados prioritariamente à pesquisa de sítios e de objetos arqueológicos e, por outro, conservadoras/es e museólogas/os que não se interessavam por este tipo de acervo, com exceção da nossa pioneira Maria Cristina Bruno, atuante - e militante - desde os anos 1980. No entanto, com as políticas públicas de qualificação dos museus e a implantação de cursos de graduação e pós-graduação nas áreas de museologia e de conservação no cenário nacional, principalmente na última década, novos interesses, preocupações e, consequentemente, novas posturas e procedimentos têm surgido para as instituições que se dedicam a pesquisas arqueológicas e/ou que concedem endosso institucional a projetos.

Esta realidade, assim, impõe reflexões e tomadas de atitudes que visem à conservação e à documentação do patrimônio arqueológico recuperado. A produção nacional é, ainda, tímida, apesar da existência de instituições que têm desenvolvido programas de salvaguarda. Trabalhos como os de Santos (2005), Lima e Rabello (2007), Costa (2007, 2008), Witchers (2010), Ballardo (2011), Ramos (2011), Pereira (2012), Leal (2014) e Campos e Granato (2015) vêm contribuir para a construção de diálogos entre as áreas envolvidas. Esta foi uma das prerrogativas do Fórum de Arqueologia da Sociedade de Arqueologia Brasileira (SAB) - Acervos Arqueológicos ${ }^{10}$ expressa em suas recomendações, como-no Eixo Gestão de acervos arqueológicos: "A gestão de acervos deve considerar a Musealização da Arqueologia (como conceito, método e políticas públicas) e a Conservação Arqueológica como campos científicos em processo de consolidação"11.

Com o suporte da cadeia operatória da museologia, arqueólogas/os, museólogas/os e conservadoras/es podem, de forma colaborativa, implementar ações adequadas e adaptadas à gestão das grandes coleções arqueológicas que "abarrotam" as reservas técnicas. A Musealização da Arqueologia

Organiza-se a partir de estudos relativos à cadeia operatória de procedimentos museológicos de salvaguarda (conservação e documentação) e comunicação (exposição e ação educativa-cultural), aplicados à realidade arqueológica, constituída a partir de referências patrimoniais, coleções e acervos. Por um lado, estes estudos buscam o gerenciamento e preservação destes bens patrimoniais e, por outro, tem a

${ }^{10}$ O Fórum de Arqueologia da SAB - Acervos Arqueológicos, realizado em Ouro Preto entre 26 e 28 de abril de 2017, foi organizado pelo GT Acervos da Sociedade de Arqueologia Brasileira (SAB) e pelo Departamento de Museologia da Universidade Federal de Ouro Preto (UFOP).

${ }^{11}$ Recomendações de Ouro Preto/Abril-2017, pg.1 (inédito).

\begin{tabular}{|l|l|l|l|l|l|l|}
\hline (c) Rev. Arqueologia Pública & Campinas, SP & v.11 & n.2 & p. 8 & Novembro/2017 & ISSN 2237-8294 \\
\hline
\end{tabular} 


\section{ARTIGO}

potencialidade de cultivar as noções de identidade e pertencimento. (BRUNO, 2007a, p. 1 apud WITCHERS, 2010, p. 48).

Como as instituições de guarda e pesquisa que recebem acervos arqueológicos podem participar do movimento de qualificação da gestão deste patrimônio material finito? Consideramos que é imperativa a elaboração e/ou adequação de parâmetros mínimos que regulem a entrada destes acervos nas reservas técnicas institucionais. Também é recomendável a adoção de critérios unificados em nível regional com relação aos protocolos de ingresso, contribuindo para evitar, dessa forma, o deslocamento de coleções fora de suas áreas de ocorrência.

Foi nesta direção, e contando com as experiências e reflexões sobre a gestão de acervos, que as/os profissionais do Laboratório Multidisciplinar de Investigação Arqueológica (LÂMINA), da Universidade Federal de Pelotas (UFPel), e do Museu Joaquim José Felizardo, da Secretaria Municipal de Cultura de Porto Alegre (SMC), reuniram-se para pensar e elaborar, de modo coletivo, uma proposta de instrumento a ser empregado na salvaguarda de bens arqueológicos. Esta sugestão de Protocolo de ingresso de acervos arqueológicos apresenta orientações quanto à preservação dos materiais arqueológicos recuperados, desde o planejamento e execução dos trabalhos de campo e de laboratório, às atividades de conservação e documentação, normatizando a sua entrada nos locais de guarda e pesquisa.

Os protocolos de ingresso objetivam normatizar a entrada de coleções arqueológicas nas instituições e são um instrumento de gestão direcionados à preservação do patrimônio arqueológico. O Protocolo aqui apresentado, estruturado conforme a situação atual com a qual se depara o patrimônio móvel arqueológico nas instituições brasileiras, parte dos pressupostos de que as coletas de materiais arqueológicos são muitas vezes realizadas sem critérios definidos; a perda de informações de tais materiais e dos contextos de escavação por deficiências nas estratégias de documentação; o comprometimento dos artefatos e ecofatos coletados, no que se refere aos componentes materiais, informacionais e simbólicos, devido à falta ou falhas na aplicação dos procedimentos de conservação preventiva e curativa in situ, nos laboratórios e nas reservas técnicas institucionais; a carência ou ineficiência nos processos de externalização destes vestígios e a falta de ações que visem à proteção dos sítios arqueológicos pós-escavação formam parte de um arcabouço de fatores que acabam deteriorando, de forma muito grave, o patrimônio arqueológico (LIMA \& RABELLO, 2007; LAIA \& ARCURI, 2016).

Sendo assim, os referidos documentos visam assegurar a conservação, a documentação, a análise e a interpretação dos objetos e, também, a melhorar a \begin{tabular}{|l|l|l|l|l|l|l|}
\hline (C) Rev. Arqueologia Pública & Campinas, SP & v.11 & n.2 & p. 9 & Novembro/2017 & ISSN 2237-8294 \\
\hline
\end{tabular} 
sistematização das informações e potencializar os processos de musealização, de modo a fortalecer a contribuição da arqueologia com as demandas das sociedades atuais e futuras. Devidamente planejados, os protocolos de ingresso são instrumentos de gestão que orientam as atividades da equipe arqueológica nos diversos âmbitos de trabalho (no campo e no laboratório) e dos funcionários responsáveis pela guarda institucional das coleções no que se refere aos cuidados preventivos, como o acondicionamento, a conservação curativa, a restauração e a documentação. Permitem, também, valorizar o potencial informativo dos artefatos e as estratégias de extroversão. Deve partir da premissa de que a integridade dos artefatos arqueológicos - do ponto de vista informacional e material - e seu valor de comunicação dependem dos critérios de coleta e das metodologias de trabalho adotados no campo e no laboratório, prévios ao seu ingresso nas instituições de salvaguarda. Por isso, orientam os trabalhos desde o momento da extração dos materiais, reduzindo e/ou evitando danos nestes e preservando seu potencial de pesquisa e de extroversão. O protocolo almeja, inclusive, que a situação futura dos sítios arqueológicos pós-intervenção seja contemplada desde a fase de elaboração do projeto.

A proposta de protocolo que aqui apresentamos utilizou, como base, os regramentos (como as portarias do IPHAN) e as recomendações vigentes, os documentos existentes nas duas instituições (como os protocolos) - LÂMINA/UFPel e Museu -, bem como a produção dos autores mencionados. Além destas fontes, têm sido de grande ajuda os trabalhos publicados nos Cadernos Tópicos em Conservação Preventiva, pelo LACICOR-EBA-UFMG (FRONER \& SOUZA, 2008a e b; SOUZA \& FRONER, 2008a e b; SOUZA, 2008) e os protocolos de ingresso do Sistema de Museos de Colônia del Sacramento - Uruguai (COMISIÓN DEL PATRIMONIO CULTURAL DE LA NACIÓN, 2011), dos museus da Dirección de Bibliotecas Archivos y Museos - Chile (SEGUEL \& QUIROZ, 2006) e do Museo de Cádiz - Espanha (ALONSO, LÓPEZ, ZAMBRANO, 2009).

\section{O PROTOCOLO DE INGRESSO DE ACERVOS ARQUEOLÓGICOS}

A. Este Protocolo respeita as normatizações apresentadas na Portaria do IPHAN no 07, de 1988, na Instrução Normativa do IPHAN no 01, de 2015, e na Portaria do IPHAN no 196, de 2016, bem como as Recomendações de Ouro Preto/abril-2017, elaboradas durante o Fórum de Arqueologia da SAB - Acervos Arqueológicos.

B. Este documento deverá ser complementado por um termo assinado pelas(os) arqueólogas(os) responsáveis pela pesquisa arqueológica e pelas(os) responsáveis pelos 
empreendimentos, no caso de processos ligados ao licenciamento ambiental, no qual as/os próprios se comprometem a cumprir o colocado no Protocolo.

C. A entrega dos materiais arqueológicos deverá ser feita mediante prévio agendamento e as diretrizes descritas no presente Protocolo precisam ser observadas.

D. Caso o estado de conservação dos artefatos a serem depositados na Instituição estejam em desacordo com as condições descritas no Protocolo, os responsáveis poderão ingressálos novamente depois dos devidos tratamentos.

E. Os objetivos e a problemática do projeto devem estar voltados para produção de conhecimento do local e/ou da região. O projeto deverá orientar e possibilitar a definição de critérios sobre o que será efetivamente coletado no trabalho de campo.

F. Deverão ser previstas reuniões de trabalho com a equipe técnica da instituição nos períodos de realização dos trabalhos de campo e de laboratório, visando o acompanhamento dos procedimentos de triagem e de curadoria dos materiais arqueológicos, bem como a seleção daqueles que irão compor a Coleção ou Acervo de Referência do sítio arqueológico.

G. Prever ações conjuntas entre a instituição de guarda e pesquisa e equipes de projetos, visando potencializar ações educativas sobre o patrimônio arqueológico.

H. O projeto de pesquisa deve incluir pelo menos um profissional da área da Conservação e Restauração desde a fase de planejamento e, se possível, um da área da Museologia.

I. A/o contratante e a/o responsável pelo Projeto de Pesquisa deverão disponibilizar, a critério da instituição, as facilidades necessárias para o acompanhamento das atividades de campo e de laboratório.

\section{QUANTO À DOCUMENTAÇÃO PARA A SOLICITAÇÃO DE ENDOSSO INSTITUCIONAL}

O proponente apresentará uma solicitação de endosso institucional e cópia do Projeto de Pesquisa ${ }^{12}$, detalhando:

1.1. Listagem da equipe participante, incluindo responsabilidades e dedicação estimada.

1.2. Diagnóstico dos condicionantes ambientais ${ }^{13}$ do local de escavação incluindo: tipo de sedimento (arenoso, argiloso, limoso, combinações); condições em que o sedimento se encontra (seco, úmido, alagado); $\mathrm{pH}$ do solo (valor absoluto, indicando como foi feita a medição); drenagem (boa, média, deficiente); posição na paisagem (topo de encosta, terço

${ }^{12}$ Caso se trate de um projeto desenvolvido em área quilombola ou numa área de preservação ambiental, o Contratante deve estar ciente da obrigatoriedade da autorização correspondente do Instituto Chico Mendes de Conservação da Biodiversidade (ICMBio).

${ }^{13} \mathrm{O}$ diagnóstico não deverá ser anterior a 24 meses da solicitação de endosso institucional.

\begin{tabular}{|l|l|l|l|l|l|l|}
\hline () Rev. Arqueologia Pública & Campinas, SP & v.11 & n.2 & p. 11 & Novembro/2017 & ISSN 2237-8294 \\
\hline
\end{tabular} 
superior, terço médio, terço inferior, planície); usos do solo atuais e passados (agrícola, pastagem intensiva, pradaria natural, mata ciliar, floresta, banhado, restinga, palmar, campo arbustivo, ocupação urbana ou suburbana [especificar] etc.); aplicação de pesticidas e ou fertilizantes químicos; forma de uso do solo (plantio direto, plantio convencional etc.); profundidade do lençol freático e variações significativas do seu nível; outras informações que sejam consideradas pertinentes.

1.3. Descrição dos cuidados de conservação preventiva a serem tomados durante as etapas de campo, transporte e laboratório com relação aos artefatos arqueológicos.

\subsection{Relação dos insumos a serem utilizados nos procedimentos de conservação} preventiva, indicados pelo diagnóstico dos condicionantes ambientais.

1.5. Critérios norteadores sobre o que será coletado no trabalho de campo.

1.6. Conjunto de medidas de proteção do sítio arqueológico pós-escavação. Potenciais medidas de conservação do sítio a posteriori do trabalho arqueológico (cartazes, cercados, recobrimento, reforço de estruturas, coberturas; reflorestamento, treinamento de guias locais, sensibilização, musealização etc.) deverão ser propostas no projeto. Fica a critério da instituição avaliar, conjuntamente com o contratante, a viabilidade de levar a cabo algumas das medidas propostas.

\section{DOCUMENTAÇÃo A SER ENTREgue PELO PROPONENTE NA ETAPA DE INGRESSO DO ACERVO ARQUEOLÓGICO}

\subsection{Documentação original produzida em campo e em laboratório ${ }^{14}$}

2.1.1. Toda a documentação original produzida em campo e em laboratório, como diários de campo (manuscritos a lápis e/ou impressos), registros audiovisuais, desenhos, plantas, croquis, laudos laboratoriais, fichas de análise, fichas de catálogo e/ou inventário, os relatórios parciais e o relatório final ${ }^{15}$ impressos, acompanhados de meios digitais com os textos e imagens, devem ser entregues à instituição após a pesquisa concluída, e acondicionados em pastas de polipropileno cor cristal (com elástico). Também deverão ser anexadas as informações secundárias relevantes sobre o sítio, como registros históricos, iconografia, estudos anteriores etc.

2.1.2. A documentação deve ser separada por sítios ou áreas de ocorrência arqueológica (AOA), inclusive os diários de campo.

\footnotetext{
${ }^{14}$ A extensão dos distintos tipos de arquivos digitais deverá ser consultada na instituição.

${ }^{15}$ Os relatórios devem estar encadernados em espiral de plástico com as imagens impressas em cores.
} 
2.1.3. O prazo para entrega da documentação original produzida em campo e em laboratório não deve ultrapassar doze meses após a entrega dos relatórios relativos aos trabalhos de campo realizados.

2.1.4. Em separado (em invólucros plásticos, tamanho A4), devem ser entregues os seguintes documentos impressos e em meio digital:

a) Formulário de Sítio Arqueológico do Sistema de Gestão do Patrimônio Arqueológico, atualizado, do Cadastro Nacional de Sítios Arqueológicos (IPHAN), em Access.

b) Fichas de Catálogo e/ou de Inventário de material arqueológico.

c) Fichas Quantitativas de material arqueológico por categoria material e especificidades.

Exemplos: lítico (categ. mat.)/quartzo (especificidade), cerâmica (categ. mat.)/roletada/Guarani/ (especificidade), metal (categ. mat.)/ferro (especificidade), louça (categ. mat.)/faiança (especificidade).

d) Listagem de Caixas, na qual deve constar o nome do Sítio/AOA, categorias materiais/especificidades, números de catálogo; total de invólucros e total de objetos por caixa.

e) Listagem das Fotografias realizadas em campo, em laboratório, em atividades educativas, entre outras: identificação das pastas, subpastas (se houver) e das fotos (local; autoria; data; observação ${ }^{16}$ ). Em pelo menos uma das identificações deve constar o local e/ou a atividade registrada. É necessário informar as legendas das identificações escolhidas.

f) Ficha de Cadastro de Bem Arqueológico Móvel (segundo Portaria 196, 18/05/16, Anexo II, IPHAN). Esta Ficha é utilizada para compor o Termo de Recebimento de Acervo Arqueológico (segundo Portaria 196, 18/05/16, Anexo III, IPHAN).

g) Listagem dos materiais que demandam cuidados especiais. Estes materiais, seja pela sua estrutura, composição, estado, grau de vulnerabilidade, raridade ou excepcional valor informativo, devem estar devidamente individualizados, facilitando, desta forma, seu rápido acondicionamento e monitoramento na reserva técnica.

h) Descrição dos critérios de coleta e triagem do material arqueológico adotados durante a pesquisa ${ }^{17}$.

${ }^{16} \mathrm{Na}$ câmera fotográfica, devem estar ajustadas a data e hora da fotografia para que estas informações apareçam nos metadados desta e, se for possível, que constem os dados do GPS interno da câmera.

${ }^{17}$ Os critérios de coleta e de triagem, adotados no campo e no laboratório, possibilitam a redução da quantidade de artefatos a serem patrimonializados, evitando a acumulação de materiais nas reservas técnicas e sua degradação gradual. Estes critérios frequentemente tomam como base os seguintes elementos: materialidade do artefato, dimensões, unicidade, capacidade informacional, redundância etc.

\begin{tabular}{|l|l|l|l|l|l|l|}
\hline (C) Rev. Arqueologia Pública & Campinas, SP & v.11 & n.2 & p. 13 & Novembro/2017 & ISSN 2237-8294 \\
\hline
\end{tabular} 
i) Listagem de objetos, com informações associadas, que possuam potencial para extroversão e para comporem a Coleção ou Acervo de Referência do sítio arqueológico, segundo critérios informados pela instituição de guarda e pesquisa.

2.2 Originais ou cópias da produção científica e técnica relacionada à pesquisa realizada, como publicações, apresentações em eventos, vídeos, material de divulgação; ações de educação patrimonial, cartilhas, banners, entre outras, devem compor a documentação a ser entregue impressa e/ou em formato digital. Estes documentos podem ser entregues na medida que forem sendo produzidos, possibilitando a atualização dos registros junto à instituição de guarda do acervo.

2.3. Dossiê referente à conservação preventiva e curativa dos materiais. Este documento deve incluir as seguintes informações ${ }^{18}$ :

2.3.1. Registro dos ambientes de depósito dos artefatos, detalhando: tipo de sedimento; conteúdo de água (seco, úmido, alagado); pH do solo; drenagem; posição na paisagem; usos do solo (atuais e passados); aplicação de pesticidas/fertilizantes químicos; forma de uso da terra; profundidade do depósito; profundidade do lençol freático e variações significativas do seu nível; outras informações que sejam consideradas pertinentes.

\subsubsection{Registro do estado de conservação do conjunto dos artefatos, por categoria} material ${ }^{19}$, no momento da coleta, especificando: grau de conservação; estado de fragmentação; estrutura; patologias (desalcalinização vítrea, desvitrificação, oxidação ativa de materiais metálicos, eflorescências, camadas de óxidos e ou sedimentos, depósitos minerais superficiais, depósitos calcários, ocorrência de fissuras e ou gretas, esfarelamento superficial, fragilidade estrutural, evidenciada pela baixa resistência a pressões, ataques biológicos, ressecamento em materiais orgânicos, degradação química pela ação de poluentes) e outras informações que sejam consideradas pertinentes.

Observação: Os objetos que estejam muito recobertos por depósitos minerais, inviabilizando sua identificação e estudo, e que não possam ser limpos sem que sua integridade seja colocada em risco, deverão ser radiografados previamente e as radiografias deverão ser anexadas ao relatório.

2.3.3. Registro dos cuidados de conservação preventiva adotados em campo. Dever-seá indicar os cuidados tomados para evitar danos nos artefatos extraídos, como sombreamento, proteção contra o vento, medidas de segurança contra furtos e/ou

\footnotetext{
${ }^{18} \mathrm{O}$ dossiê contendo as informações referentes aos cuidados preventivos e aos procedimentos de conservação curativa e/ou restauro será redigido e assinado por um Conservador-Restaurador com experiência em curadoria de coleções arqueológicas ou por um especialista igualmente qualificado.

${ }^{19}$ Material ósseo, malacológico, cerâmico, vítreo, metálico, couro, madeira, borracha, tecido etc.

\begin{tabular}{l|l|l|l|l|l|l|}
\hline (c) Rev. Arqueologia Pública & Campinas, SP & v.11 & n.2 & p. 14 & Novembro/2017 & ISSN 2237-8294
\end{tabular}
} 


\section{ARTIGO}

\section{Revista de Arqueologia Pública}

vandalismo; equipamentos e insumos de conservação, infraestrutura utilizada para a conservação preventiva e conservação curativa.

2.3.4. Registro dos métodos de coleta dos objetos, especificando data e metodologia empregada, a saber: sem método específico; levantamento pós-consolidação (informar consolidante empregado, diluição, solvente, forma de aplicação, número de aplicações, tempo entre a pré-consolidação e a retirada do objeto); levantamento em bloco sem consolidante e sem reforços; levantamento em bloco com reforço de vendas (com ou sem consolidante); levantamento em bloco com consolidação de tal; outros procedimentos; responsável do procedimento.

\subsubsection{Registro dos procedimentos de conservação curativa efetuados nos artefatos in} situ, especificando: método de secagem; método de limpeza química ou física (especificando solventes empregados e instrumental); método de pré-consolidação (informando consolidante, diluição, solvente, forma de aplicação e número de aplicações); tratamento eletrolítico; montagem de fragmentos (detalhando o produto empregado, diluição e solvente, e a metodologia empregada); métodos de análise (imã, lupa de mão, lupa estereoscópica etc.); outras informações que sejam consideradas pertinentes e o responsável pelas atividades.

2.3.6. Registro das condições de embalagem e transporte do material do sítio arqueológico ao laboratório e deste para a instituição de guarda e pesquisa, especificando: material das caixas e dos invólucros; rotulagem; produtos de acolchoamento; produtos de dessecação; método de acondicionamento dos materiais; método de transporte.

2.3.7. Registro dos procedimentos de conservação curativa realizados no laboratório, detalhando análises e tratamentos efetuados, entre outras informações. Incluir datas dos procedimentos e o responsável técnico.

2.3.8. Registro dos Procedimentos de restauro, detalhando: objetivos dos procedimentos, materiais e metodologias empregadas. Incluir datas dos procedimentos e o responsável técnico. 2.3.9. Conjunto de medidas de preservação do sítio arqueológico pós-escavação (diferenciando entre as medidas recomendadas, as efetivamente realizadas e as de futura realização pelo proponente).

\section{QUANTO À GESTÃO DOS MATERIAIS ARQUEOLÓGICOS}

\subsection{Em campo}

3.1.1. As coletas devem responder aos objetivos da pesquisa, considerando possibilidades de futuras pesquisas a serem desenvolvidas no sítio arqueológico e que possam responder a questões posteriores. 
3.1.2. Os critérios de coleta e triagem de material arqueológico apresentados no Projeto deverão ser seguidos durante o trabalho de campo.

3.1.3. No caso de material construtivo (telhas, tijolos, vidros, pregos, cravos, reboco, pisos etc.) deverão ser coletadas amostras representativas do conjunto.

3.1.4. Os artefatos que não respondam às questões da pesquisa em desenvolvimento e que possuam capacidade informacional devem ser documentados (registro fotográfico e georeferenciamento) e não coletados. A sua integridade não deve ser descaracterizada.

3.1.5. Procedimentos de conservação preventiva deverão ser adotados para evitar danos aos artefatos: utilização de uma cobertura para sombreamento, barreiras contra o vento e a areia; emprego de infraestrutura existente como laboratório de campo ou montagem provisória de um local de trabalho para o acondicionamento e armazenagem transitório dos materiais etc.

3.1.6 A extração de artefatos fragmentados ou fragilizados deve ser realizada com as técnicas apropriadas.

3.1.7. As ações de conservação preventiva e/ou curativa realizadas no campo devem ser documentadas utilizando fichas adequadas e fotografias.

3.1.8. Selecionar as peças que estejam fragilizadas que necessitem futuras intervenções de conservação curativa em laboratório.

3.1.9. Embalar os objetos em invólucros plásticos de polietileno ou polipropileno fechados e perfurados com alfinetes, contendo no seu interior as etiquetas de identificação igualmente embaladas em invólucros plásticos.

3.1.10. Não retirar os sedimentos aderidos às peças ${ }^{20}$.

3.1.11. Separar as peças arqueológicas por categoria material para serem acondicionadas.

3.1.12. Evitar colocar muitos fragmentos em um mesmo invólucro para reduzir atritos ${ }^{21}$.

3.1.13. Envolver com filme plástico de polietileno com bolhas as peças que não couberem em invólucros de polietileno.

3.1.14. Acondicionar os materiais oriundos de meios úmidos em dupla embalagem.

3.1.15. Acondicionar os materiais oriundos do meio aquático acompanhados com o mesmo líquido de procedência. Os mesmos deverão permanecer em invólucros fechados, na

\footnotetext{
${ }^{20}$ A limpeza dos sedimentos aderidos, caso necessário, deve ser feita em laboratório, a seco, com instrumental apropriado e sob uma lupa de mesa, lupa estereoscópica ou lupa de pala. Em alguns casos, poderá ser necessário o uso de solventes (álcool, acetona etc.), de água destilada ou de outras substâncias químicas.

${ }^{21} \mathrm{Na}$ arqueologia urbana, a quantidade de peças pode chegar a ser extremadamente elevada num mesmo local de coleta, justificando-se o emprego de um mesmo invólucro para acondicionar diversas peças. Já na arqueologia pré-histórica, recomenda-se que cada artefato seja acondicionado de forma individual, evitando, não somente a degradação por atrito, mas principalmente a contaminação de micro vestígios entre os artefatos.
}

\begin{tabular}{|l|l|l|l|l|l|l|}
\hline (C) Rev. Arqueologia Pública & Campinas, SP & v.11 & n.2 & p. 16 & Novembro/2017 & ISSN 2237-8294 \\
\hline
\end{tabular} 
escuridão, preferencialmente a baixas temperaturas, até o devido tratamento pelo especialista em conservação.

3.1.16. Não sobrepor os artefatos nas caixas para transporte, visando evitar tensão mecânica e condensação de vapor de água no interior.

3.1.17. Revestir o fundo das caixas com material de amortecimento.

\subsection{Em laboratório}

Os materiais deverão ser higienizados, identificados, separados por categoria material e especificidade, estabilizados, catalogados, quantificados, analisados, interpretados e embalados conforme os requisitos contidos neste documento.

3.2.1. Higienização ${ }^{22}$. A limpeza deverá objetivar deixar em evidência marcas, inscrições, monogramas, pinturas, baixos relevos, patologias etc., que possam fornecer informações diagnósticas, assim como permitir a análise e interpretação dos materiais.

3.2.2. Os materiais arqueológicos deverão chegar sem ter passado por lavagem com água. Caso seja necessário, o excesso de sedimentos ou material aderido deverá ser removido a seco ou com solventes diluídos em água destilada ou deionizada (álcool, acetona) com ferramentas não agressivas. Em artefatos policromados é preciso realizar teste de solubilidade antes de realizar a limpeza úmida.

3.2.3. É recomendável não remover totalmente a camada de sedimentos inorgânicos aderidos (não concrecionados) à superfície do objeto (como areia, argila, carvão etc.). Caso se faça necessária tal remoção, uma amostra do resíduo resultante deverá ser acondicionada num invólucro de polietileno com fecho hermético e identificada com a mesma numeração do objeto.

3.2.4. Caso os materiais metálicos apresentem uma pátina estável, esta deve ser preservada.

3.2.5. Quanto ao manuseio das peças: deverão empregar-se luvas descartáveis ${ }^{23}$ de látex ou nitrílica, sem pó bioabsorvível.

3.2.6. Evitar o consumo de materiais, junto aos objetos, que possam alterar ou comprometer sua conservação e futuras análises (exemplo: alimentos sólidos, líquidos, cigarros etc.).

\footnotetext{
${ }^{22}$ A limpeza deve respeitar a composição material e a fragilidade dos objetos, bem como futuras análises.

${ }^{23}$ A manipulação dos artefatos sem uso de luvas, além dos riscos de contaminação do operador por agentes biológicos e/ou substâncias químicas, pode provocar a migração de materiais (agentes de deterioração químicos e/ou biológicos, ou de microvestígios) de uma peça a outra, além de depositar ácidos graxos e outros resíduos das mãos na superfície do artefato. Estes resíduos podem absorver vapor de água e material particulado, provocando reações de oxidação em peças metálicas ou surgimento de microrganismos em peças de natureza orgânica etc.
}

\begin{tabular}{|l|l|l|l|l|l|l|}
\hline (c) Rev. Arqueologia Pública & Campinas, SP & v.11 & n.2 & p. 17 & Novembro/2017 & ISSN 2237-8294 \\
\hline
\end{tabular} 
3.2.7. Identificação. Os materiais arqueológicos devem estar devidamente identificados por meio de marcação direta (feita sobre a superfície do objeto) ou indireta (sobre um suporte externo). Dever-se-á dar preferência à marcação direta, sempre e quando as características do objeto o permitam. O número de identificação deverá seguir o modelo adotado pela instituição ${ }^{24}$ e deverá ser colocado num local do objeto que não impacte negativamente nos estudos, nos diagnósticos posteriores e na sua extroversão, e que minimize a manipulação do objeto com a finalidade de ver o número.

3.2.8. A marcação direta deverá seguir o seguinte procedimento: a) limpar a seco (se necessário) a área de rotulagem, de formato retangular e de tamanho proporcional ao código a ser registrado; pincelar uma fina camada de Paraloid $B-72^{25}$ ou $B-67^{26}$ (diluído a $25 \%$ em acetona); deixar secar completamente; escrever a numeração com tinta nanquim com caracteres pequenos e legíveis; deixar secar completamente; aplicar uma camada de Paraloid (B-72 ou B-67); deixar secar completamente antes de colocar na embalagem.

3.2.9. A marcação indireta, como no caso de peças metálicas em avançado estado de oxidação, bem como de vidro, couro, vegetal em processo de degradação etc., deve ser feita preferencialmente por meio de etiqueta de papel poliéster ou de papel alcalino. A etiqueta deve estar inserida em invólucro plástico com fecho hermético (tipo "ziploc"), escrita a lápis e amarrada com fio de nylon. Quanto a peças tramadas como têxteis, cestarias e esteiras, poderá ser também utilizada etiqueta de tecido em algodão costurada nas pontas com agulha fina e fio de poliéster.

3.2.10. Estabilização. Todos os materiais deverão ser entregues estabilizados para evitar o agravamento de patologias existentes ou o surgimento de novas patologias já dentro da reserva técnica. Por "estabilizados" entendem-se aqueles objetos que não apresentam processos de instabilidade química e/ou física. Como exemplos de materiais arqueológicos não estabilizados, podem-se citar: artefatos ferrosos com corrosão ativa; objetos de cobre ou de bronze ou de outras ligas com pátina ativa ("doença-do-cobre"); elementos de chumbo com oxidação ativa; artefatos mistos metálicos com corrosão galvânica; objetos com quebras, perdas, desagregação e/ou fissuras que podem provocar perda da sua integridade física; artefatos de vidro com sintomas de desalcalinização ou de desvitrificação, evidenciados pelo surgimento de opalescência, iridescência, descamação e ou exsudação; materiais com alto teor interno de sais (como objetos líticos, cerâmicos, metálicos ou outros provenientes de sítios subaquáticos marinhos, estuarinos ou de solos salinos); materiais

${ }^{24} \mathrm{O}$ código de numeração empregado na identificação dos artefatos deverá aparecer também nos registros de campo, no registro gráfico, nas fichas de conservação e nos demais documentos.

${ }^{25}$ Denominação comercial de um polímero acrílico de metil metacrilato e butil metacrilato.

${ }^{26}$ Denominação comercial de um polímero acrílico de metacrilato de isobutilo.

\begin{tabular}{|l|l|l|l|l|l|l|}
\hline () Rev. Arqueologia Pública & Campinas, SP & v.11 & n.2 & p. 18 & Novembro/2017 & ISSN 2237-8294 \\
\hline
\end{tabular} 


\section{ARTIGO}

\section{Revista de Arqueologia Pública}

cerâmicos, ósseos ou malacológicos em processos de desagregação; objetos orgânicos com indício de ataque biológico ativo; madeiras de origem subaquática sem tratamento adequado; documentos em papel com sintomas de acidificação; objetos de couro em processo de ressecamento; objetos cerâmicos ou pétreos com eflorescências salinas e objetos com evidências de contaminação química. Os tratamentos de conservação curativa devem ser executados por uma/um profissional da Conservação-Restauração especializada/o em curadoria de coleções arqueológicas ou especialista com a devida experiência. Todos os procedimentos devem ser devidamente documentados ${ }^{27}$ por meio de fichas de conservação específicas junto com o registro fotográfico correspondente, apresentadas de forma impressa e em formato digital.

3.2.11. Quantificação. Visando a obtenção de resultados relacionados à forma e à função das peças arqueológicas, adequados às necessidades da instituição, as amostras devem ser quantificadas por fragmentos, pelo número mínimo de peças (NMP) e analisadas por $\mathrm{NMP}^{28}$.

3.2.12. Caso seja necessária a colagem de peças arqueológicas, utilizar cola neutra a base acetato de polivinila ou Paraloid B-72.

3.2.13. Dentre os materiais recuperados, indicar aqueles que irão compor a Coleção ou Acervo de Referência do sítio arqueológico. Os critérios para indicação devem ser discutidos com a equipe técnica da instituição.

3.2.14. Embalagem dos materiais arqueológicos. $O$ material, separado por categoria material e sua especificidade, deve estar embalado em invólucros de polietileno transparentes de 0,05 $\mathrm{mm}$ a 0,08 $\mathrm{mm}$ com fecho hermético (tipo "ziploc"), perfurados para evitar a condensação de vapor de água no seu interior.

3.2.15. Dados de Identificação. Cada invólucro deve ter uma etiqueta com dados de identificação relativos à procedência no sítio arqueológico, à categoria material e sua especificidade, com seu(s) número(s) de catálogo, o número total de fragmentos e o número mínimo de peças (NMP), as datas do trabalho de campo e de laboratório. A etiqueta deve estar embalada também em invólucro de polietileno. Utilizar lápis para o registro. No canto direito superior de cada, etiqueta devem ser registrados os números da caixa e do invólucro. Para peças maiores, as etiquetas de identificação devem ser amarradas nas mesmas com fio sintético, como nylon.

\footnotetext{
${ }^{27}$ Estes registros são importantes para auxiliar futuros tratamentos de conservação e as atividades de monitoramento, assim como para subsidiar a extroversão.

${ }^{28}$ Por exemplo: pasta - faiança fina; esmalte - pearlware; técnica decorativa - transferprinting; padrão - Willow; forma - prato raso; diâmetro - $22 \mathrm{~cm}$. Total de fragmentos: 05; NMP: 01.

\begin{tabular}{|l|l|l|l|l|l|l|}
\hline (C) Rev. Arqueologia Pública & Campinas, SP & v.11 & n.2 & p. 19 & Novembro/2017 & ISSN 2237-8294
\end{tabular}
} 
3.2.16. Amortecimento. Estruturar o interior dos invólucros com manta de espuma de polietileno expandido (como Ethafoam) de $3 \mathrm{~mm}$ de espessura, protegendo as peças contra impactos, atritos e pressões.

3.2.17. Evitar colocar muitos fragmentos em um mesmo invólucro para reduzir atritos e para que tal não se abra. As peças maiores que não couberem no interior dos invólucros plásticos definidos devem ser envoltas em mantas de não-tecido, preferencialmente as produzidas com fibras de polietileno prensadas (Tyvek, por exemplo), ou em não tecido de filamentos contínuos de polipropileno (como TNT) brancos.

3.2.18. Não devem ser utilizadas fitas adesivas de qualquer natureza e/ou objetos metálicos (clipes e grampos) como parte da identificação e do acondicionamento do material.

3.2.19. Acondicionar, em invólucros individuais, peças inteiras, peças com grande parte de seu corpo preservado ou reconstituído por meio de colagem, fragmentos de uma mesma peça (formando um conjunto) e fragmentos únicos de peças consideradas relevantes e/ou delicadas.

3.2.20. Acondicionamento dos materiais arqueológicos. $O$ acondicionamento do material arqueológico por categoria material deve ser feito em caixas plásticas ${ }^{29}$ empilháveis, brancas, opacas; de polietileno e/ou polipropileno, rígidas e com tampas devidamente identificadas conforme modelo de etiqueta adotado pela Instituição. Para objetos que não couberem nas caixas mencionadas, utilizar contentores plásticos maiores e rígidos. Cobri-los preferencialmente com Tyvek ou TNT, se não possuírem tampas.

3.2.21. Materiais menores de $0,5 \mathrm{~cm}$ poderão ser embalados em contentores rígidos de polietileno ou polipropileno de tamanho proporcional a eles, com tampa (tipo tubo Eppendor ${ }^{30}$, por exemplo) ou em invólucros de polietileno transparentes de fecho hermético.

3.2.22. Os fundos das caixas devem ser revestidos internamente com manta de espuma de polietileno expandido (como Ethafoam) de $10 \mathrm{~mm}$ de espessura para proteção contra impactos. Para que não haja comprometimento da integridade do acervo, as caixas não devem ficar muito cheias e nem muito pesadas.

3.2.23. Cada caixa deve conter uma categoria material e ser identificada por uma etiqueta conforme modelo empregado pela instituição, aderida em uma das duas faces mais estreitas. No canto direito da etiqueta, deve constar o número sequencial de cada caixa.

\footnotetext{
${ }^{29}$ Os tamanhos das caixas serão determinados pela instituição em conformidade com as dimensões do tipo de armazenamento disponível.

${ }^{30} \mathrm{O}$ tubo Eppendorf, chamado também de tubo de microcentrífuga, é um pequeno cilindro de fundo cônico de polipropileno, com tampa acoplada.
}

\begin{tabular}{|l|l|l|l|l|l|l|}
\hline (C) Rev. Arqueologia Pública & Campinas, SP & v.11 & n.2 & p. 20 & Novembro/2017 & ISSN 2237-8294 \\
\hline
\end{tabular} 


\section{ARTIGO}

\section{Revista de Arqueologia Pública}

3.2.24. Os invólucros, em cada caixa, devem ser dispostos na posição horizontal, uns sobre os outros e, no caso de pequenos objetos, na posição vertical, separados por paredes de Ethafoam.

3.2.25. Todos os artefatos que sejam vulneráveis à deterioração físico-mecânica ou se encontrem em estado de alta fragilidade deverão ser embalados em invólucros plásticos de polietileno transparente de $0,1 \mathrm{~mm}$, com fecho hermético. Estes deverão ser acondicionados numa caixa (com as características acima listadas) acolchoada com espuma de polietileno ou outros materiais inertes ${ }^{31}$ e com materiais também inertes interpostos entre os objetos para a devida imobilização dentro da caixa. A critério do especialista em conservação, também podem ser empregadas bandejas de espuma de polietileno com os artefatos acondicionados em cavidades feitas no mesmo material. Empregando-se alças de algodão, podem ser armazenadas várias bandejas dentro de uma mesma caixa. Esta situação de vulnerabilidade deve estar informada nas etiquetas do invólucro e da caixa.

3.2.26. Amostras. As amostras que requeiram a utilização de técnicas analíticas específicas (C14, ADN, pólen, fitólitos, grãos de amido etc.) deverão ser acondicionadas de acordo a este documento e com os protocolos específicos que cada técnica recomenda.

\section{ENTREGA NA INSTITUIÇÃO}

4.1. O contratante fornecerá, à instituição, estantes para o armazenamento das caixas com o material arqueológico recuperado. As estantes de aço devem ter recebido tratamento antiferruginoso por fosfatização e pintura epóxi-pó por processo eletrostático, com as medidas e características especificadas pela instituição, e com estrutura adequada para suporte de peso e dimensões do material (chapa 24 com reforço). O serviço de montagem deverá ser fornecido pelo contratante.

4.2. A entrega do material arqueológico, da documentação e das estantes deve ser agendada previamente com o setor responsável.

4.3. Para o transporte do material arqueológico, seguir as orientações que constam no Anexo I da Portaria do IPHAN no 196, de 18 de maio de 2016.

4.4. A instituição somente receberá o acervo arqueológico se os itens que constam neste Protocolo e no termo assinado pelas(os) arqueólogas(os) responsáveis pela pesquisa arqueológica e pelas(os) responsáveis pelos empreendimentos, no caso de processos ligados ao licenciamento ambiental, houverem sido cumpridos.

${ }^{31}$ Dentre os materiais inertes aceitáveis para serem utilizados no acondicionamento de bens arqueológicos, encontram-se: espuma, flocos e folhas de polietileno; tecido de poliéster; tecido Mylar; papel com reserva alcalina; papel de seda desacidificado etc.

\begin{tabular}{|l|l|l|l|l|l|l|}
\hline (C) Rev. Arqueologia Pública & Campinas, SP & v.11 & n.2 & p. 21 & Novembro/2017 & ISSN 2237-8294
\end{tabular}


4.5. A instituição entregará o Termo de Recebimento de Acervo Arqueológico (conforme Anexo III da Portaria do IPHAN № 196) em duas vias assinadas pela sua Direção.

4.6. A/o arqueóloga/o deve entregar um artigo científico de dez a trinta laudas, com relatório sintetizando o trabalho executado, contemplando interpretações, resultados e as medidas aplicadas para conservação e extroversão dos acervos encontrados e sítios localizados. O artigo será disponibilizado às(aos) pesquisadoras(es) interessadas(os).

\section{CONSIDERAÇÕES FINAIS}

O diálogo entre arqueólogas/os, conservadoras/es e museólogas/os para a elaboração da proposta do Protocolo de ingresso mostrou-se muito importante, assegurando a inclusão de medidas relacionadas à conservação e à documentação em diferentes momentos dos trabalhos com os acervos, com implicações nos processos de análise e interpretação dos objetos. Consideramos que estas ações, executadas com responsabilidade, podem garantir a qualidade das informações e potencializar as ações de musealização e publicização do patrimônio arqueológico. Pensamos, com este protocolo, em apresentar uma possibilidade que pudesse servir para reflexões, debates e apoio para avançarmos nas discussões sobre a salvaguarda de acervos.

A publicação da Portaria do IPHAN no 196, de 2016, constituiu um grande avanço na gestão do patrimônio arqueológico, apresentando uma série de recomendações tanto para os empreendedores quanto para os pesquisadores e gestores de instituições de guarda e pesquisa. Muitos dos pontos nela apresentados servem de base para a elaboração, pelas referidas instituições, de normas que regulem o ingresso dos materiais arqueológicos, visando ao aprimoramento dos trabalhos de campo e de laboratório, resultando em coleções melhor conservadas, interpretadas e extrovertidas. Portanto, as instituições podem ter, no protocolo de ingresso, um instrumento para gerenciar a salvaguarda do acervo arqueológico, potencializando a interface entre a instituição e a sociedade. 


\section{REFERÊNCIAS BIBLIOGRÁFICAS}

ALONSO, J. de La S. F.; LÓPEZ, M. D. de la O.; ZAMBRANO, L. C. Protocolo de entrega de materiales arqueológicos como depósitos de la Junta de Andalucía en el Museo de Cádiz. 2009.

Disponível em: http://web.archive.org/web/20100619135020/http://www.museosdeandalucia.es/cultura/mus eos/MCA/index.jsp?redirect=S2_1.jsp. Acesso em: 19/06/2010 às 15:38.

BALLARDO, L. O. M. Documentação museológica: a elaboração de um sistema documental para acervos arqueológicos e sua aplicação no Laboratório de Estudos e Pesquisas Arqueológicas/UFSM. Santa Maria: Universidade Federal de Santa Maria, p. 126, 2013. (Dissertação de Mestrado. Programa de Pós-Graduação Profissionalizante em Patrimônio Cultural)

CAMPOS, G. do N; GRANATO, M. Cartilha de Orientações gerais para Preservação de Artefatos Arqueológicos Metálicos. Rio de Janeiro: Museu de Astronomia e Ciências Afins, 2015.

COMISIÓN DEL PATRIMONIO CULTURAL DE LA NACIÓN. Protocolo de actuación arqueológica para Colonia del Sacramento: Barrio Histórico y área de amortiguación. 2011.

Disponível

em: http://www.patrimoniouruguay.gub.uy/innovaportal/file/33484/1/protocolo-arqueologia-3.pdf. Acesso em: 19/10/2011 às 14:12.

COSTA, C. A. S. Proposta de instrumento documental museológico complementar para as coleções arqueológicas do MAE/UFBA. Revista Eletrônica Jovem Museologia, vol. 2, ㄲo 4 , p. $4 / 26,2^{\circ}$ semestre 2007 .

A materialidade de uma relação interdisciplinar. Revista Museu, p. 1-6, postado em 30 dez 2008\13:26 por Editoria RM.

FRONER, Y., SOUZA, L. A. C. Prevenção de bens patrimoniais: conceitos e critérios. Tópicos em Conservação Preventiva 3. Belo Horizonte: LACICOR-EBA-UFMG, 2008a.

FRONER, Y.; SOUZA, L. A. C. Controle de pragas. Tópicos em Conservação Preventiva 7. Belo Horizonte: LACICOR-EBA-UFMG, 2008b.

IPHAN. Portaria no 07, de 01 de dezembro de 1988. Diário Oficial [da] República Federativa do Brasil. Brasília, DF, 15 dez., 1988.

IPHAN. Portaria no 196, de 18 de maio de 2016. Diário Oficial [da] República Federativa do Brasil. Brasília, DF, 2016.

IPHAN. Instrução Normativa no 01, de 25 de março de 2015. Diário Oficial [da] República Federativa do Brasil. Brasília, DF, 2015.

LAIA, P. O; ARCURI, M. M. S. Os Desafios da Musealização: as instituições de guarda do patrimônio arqueológico e o passivo das coleções provenientes do licenciamento ambiental. Anais do 4ํㅗㄴ Seminário Preservação de Patrimônio Arqueológico. Rio de Janeiro: Museu de Astronomia e Ciências Afins, p. 220-232, 2016.

LEAL, A. P. da R. Arqueologia, Museologia e Conservação: Documentação e Gerenciamento da Coleção proveniente do Sítio Santa Bárbara (Pelotas-RS). Pelotas: 
Universidade Federal de Pelotas, p. 126, 2014. (Dissertação de Mestrado. Programa de Pós-Graduação em Antropologia)

LIMA, T. A.; RABELLO, A. M. C. Coleções arqueológicas em perigo: o caso do Museu Nacional da Quinta da Boa Vista. Revista do Patrimônio Histórico e Artístico Nacional. IPHAN: Rio de Janeiro, n. 33, p. 245-274, 2007.

PEREIRA, D. Perspectivas da Curadoria Arqueológica: O caso do Laboratório de Arqueologia Peter Hilbert. Macapá: Universidade do Estado do Amapá, p. 84, 2012. (Monografia de Especialização. Curso de Especialização em Patrimônio Arqueológico da Amazônia).

RAMOS, R. N. Políticas de preservação para acervos arqueológicos. Cadernos do LEPAARQ: Textos de Antropologia, Arqueologia e Patrimônio, Pelotas: UFPel, v. VIII, no 15/16, p. 11-26, 2011.

SANTOS, A. M. P. A Conservação dos Acervos no Museu Arqueológico de Sambaqui de Joinville - MASJ. Cadernos do CEOM, n.21. Chapecó: Argos, p. 227-242, 2005.

SEGUEL, R.; QUIROZ, D. Estándares para la recepción de materiales arqueológicos en los museos de la DIBAM, Versión $\mathrm{N}^{\circ}$ 2. Santiago de Chile: Centro Nacional de Conservación y Centro de Documentación de Bienes Patrimoniales, 2006.

SOUZA, L. A. C. Conservação preventiva: controle ambiental. Tópicos em Conservação Preventiva 5. Belo Horizonte: LACICOR-EBA-UFMG, 2008.

SOUZA, L. A. C.; FRONER, Y. Reconhecimento de materiais que compõem acervos. Tópicos em Conservação Preventiva 4. Belo Horizonte: LACICOR-EBA-UFMG, 2008a.

SOUZA, L. A. C.; FRONER, Y. Roteiro de avaliação e diagnóstico de conservação preventiva. Tópicos em Conservação Preventiva 1. Belo Horizonte: LACICOR-EBAUFMG, 2008b.

WITCHERS, C. A. de M. Museus e Antropofagia do Patrimônio Arqueológico: (Des) Caminhos da Prática Brasileira. Lisboa: Universidade Lusófona de Humanidades e Tecnologia, p. 461, 2010. (Tese de Doutorado - Departamento de Museologia). 